\title{
Implications of fecal pellet size and zooplankton behaviour to estimates of pelagic-benthic carbon flux
}

\author{
Craig W. Emerson \& John C. Roff* \\ College of Biological Science, Department of Zoology, University of Guelph, Guelph, Ontario N1G 2W1, Canada
}

\begin{abstract}
Numbers, volumes and carbon content of fecal pellets collected by sediment traps and bottle casts were measured with an image analysis system, from samples collected in the lower Bay of Fundy, Atlantic Canada. Analysis of sinking, resuspension and biodegradation rates indicated that small fecal pellets must be heavily grazed within the water column. Measurement of rates of coprophagy and vertical distribution of pellets without peritrophic membranes may lead to estimates of resuspension. Differences in size-frequency spectra of pellets collected in $5 \mathrm{~h}$ and $24 \mathrm{~h}$ sediment trap developments indicated that large fecal pellets which reach the benthos are produced primarily by migratory copepods and euphausids. The effects of diel vertical migration may bias estimates of pellet carbon flux made from short sediment-trap deployments.
\end{abstract}

\section{INTRODUCTION}

The measurement of particulate fluxes is vital to the understanding of biological marine processes (Soutar et al. 1977. Suess 1980), yet hydrodynamic and biological factors which influence the measurement and interpretation of sedimentation data are not well understood. In particular, sedimentation of fecal pellets, important components of pelagic-benthic energy transfer (Urrere \& Knauer 1981), is affected by many variables yet to be fully identified or quantified.

Fecal pellets produced by the larger zooplankton sink rapidly through the water column (Small et al. 1979, Komar et al. 1981, Lorenzen \& Welschmeyer 1983), and therefore potentially influence the magnitude of benthic production. In oceanic zones, areas typified by relatively low primary production, pellet export can influence and may even restrict benthic production (Dunbar \& Berger 1981, Iseki 1981a,b, Honjo et al. 1982). Recent neritic studies, however, have suggested that fecal pellets are not always important to benthic production (Wassmann 1983, Pace et al. 1984), as biodegradation, coprophagy, resuspension and mechanical breakage may prevent them from

\footnotetext{
- Addressee for correspondence
}

reaching the benthos (Smayda 1969, Oviatt \& Nixon 1975, Honjo \& Roman 1978, Tsunogai et al. 1980).

In addition, many investigators have assumed constant sedimentation rates over short sediment-trap deployment periods (e.g. Rowe \& Gardner 1979, Lorenzen et al. 1983, Wassermann 1983, Wakeham et al. 1984). For algal and detrital fluxes this may be reasonable; however fecal pellet flux may be 'aliased' (sensu Legendre \& Demers 1984), because of zooplankton vertical migration. Thus, daily or seasonal estimates of pellet contribution to total carbon flux can be biased if extrapolated from short-term collections. Longer trap deployment will clearly reduce this problem; however, technical difficulties involved in deploying traps for long periods (Iseki et al. 1980, Gardner et al. 1983), favour short deployment. A knowledge of temporal biases due to aliasing of fecal pellet and other fluxes is therefore vital in modelling energy budgets of both oceanic and coastal areas.

The following study is part of an investigation into the pelagic and benthic energy dynamics of the lower Bay of Fundy. Herein we present results of investigations on fecal pellet standing stocks and fluxes. We consider the problems associated with quantifying coprophagy, resuspension and vertical migration effects, from short-term $(<1 \mathrm{~d})$ and diel observations. 


\section{MATERIALS AND METHODS}

Sampling was conducted from May to October 1984 in the lower Bay of Fundy, eastern Canada (Fig. 1), over an average bottom depth of $100 \mathrm{~m}$ and a tidal amplitude of approximately $5.5 \mathrm{~m}$. Salinity and temperature were measured at $10 \mathrm{~m}$ intervals using a calibrated Beckman RS5 salinity/temperature probe. The depth of the euphotic zone (defined as the depth at which $1 \%$ of surface light intensity is observed) was determined using a LMA-8A Montedoro Whitney light meter.

Fecal pellet collection. Fecal pellets were collected from bottle casts and sediment traps. Replicate bottle casts were taken at 1,10,25, 60 and $100 \mathrm{~m}$ between 1000 and $1400 \mathrm{~h}$ on each sampling day using a 5 I PVC

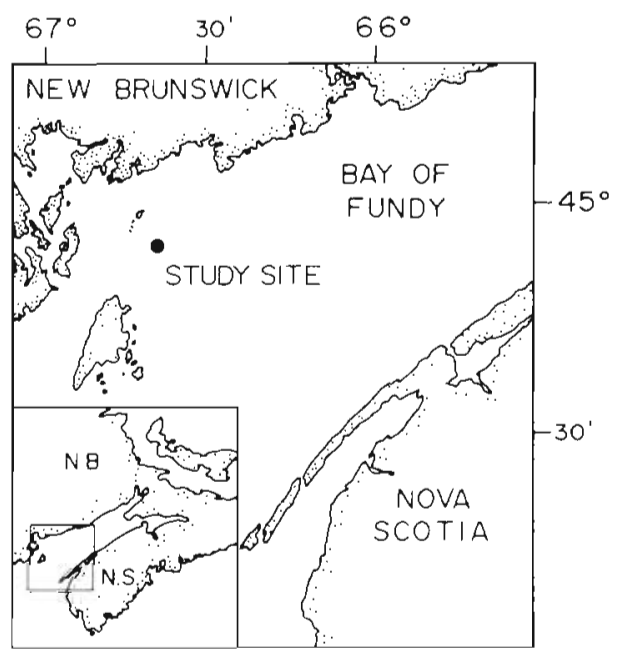

Fig. 1. Location of study area ( $)$ in the lower Bay of Fundy

Niskin sampling bottle. Samples were fixed with $5 \%$ Bouin's solution and a replicate with $0.5 \%$ acid Lugol's solution.

Fecal pellet sedimentation was determined using a floating sediment trap based on the design of Staresinic et al. (1978). Modifications included increasing the trap aspect ratio to $6(15 \mathrm{~cm}$ diameter, $90 \mathrm{~cm}$ height). A General Dynamics flowmeter was attached to the supporting cable to detect currents passing over the cylinders. Traps were deployed at the base of the euphotic zone $(25 \mathrm{~m})$, for either 5 ( \pm 1 ) daylight h or 24 $( \pm 3)$ h. No preservatives were used in the collection cylinders because of short deployment times (Emerson 1986). Approximate degradation rates of fecal pellet membranes were estimated from time/temperature series biodegradation experiments of Honjo \& Roman (1978). Sinking rates of fecal pellets were estimated from the equations of Komar et al. (1981).

Laboratory analysis. Samples were counted in a standard Wild counting chamber at 50 or $125 \times$ (for large pellets), and $250 \times$ (for smaller pellets). For high density samples, at least 40 fields were counted using the method of Sandgren \& Robinson (1984). There were no significant quantitative or qualitative differences between samples fixed in Bouin's and those fixed in acid Lugol's. Fecal pellets were measured using an image analysis system, consisting of a Leitz inverted microscope, Hitachi high resolution video camera and monitor, and a SAC Graf/Pen digitizer interfaced with an IBM-P computer. Measurements were converted to pellet spheroid or cylinder volume as appropriate, and from volume to carbon content following the relation of Johannes \& Satomi (1966) and Wiebe et al. (1976). These relations were calibrated on separated fecal pellet samples digitized as above and then processed for carbon content in a Perkin-Elmer Model $240 \mathrm{CHN}$ analyser.

Based on morphology and colour, fecal pellets were partitioned into 3 types. 'Green' pellets had a translucent green appearance (Honjo 1978), and presumably consisted of freshly egested material. 'Brown' pellets were less transparent, more dense and may have consisted of re-grazed material. It is important to note however, that colour can be affected by the distance that light travels through the pellet. Therefore, in our discussions of diel samples where large fecal pellets were present, the green and brown pellets were combined in one category, 'Intact Pellets'.

Pellets without observable peritrophic membranes (at 250x) were defined as 'Resuspended'. These are pellets which have reached the benthos, and have been resuspended after their membrane has decomposed. Fecal pellets without peritrophic membranes derived from benthic organisms may also be resuspended, although these are typically of different shapes (e.g. Risk \& Moffat 1977, Nowell et al. 1981), or sizes (e.g. Taghon et al. 1984), and would not be included in our analyses.

Calculations of pellet flux measured by the sediment trap were corrected for background pellet concentration. Statistical comparisons of pellet flux or concentrations were conducted following Sokal \& Rohlf (1981). Level of significance for all comparisons was set at alpha $=0.05$.

\section{RESULTS}

Surface temperature and salinity increased seasonally from $5^{\circ} \mathrm{C}$ and $32 \%$ in May, to $12^{\circ} \mathrm{C}$ and $34 \%$ respectively, in late summer (Fig. 2). Average temperature variation between the surface and $50 \mathrm{~m}$ was approximately $2 \mathrm{C}^{\circ}$, while salinity variation was less than $3 \%$; in October both variables were uniform throughout the water column. 


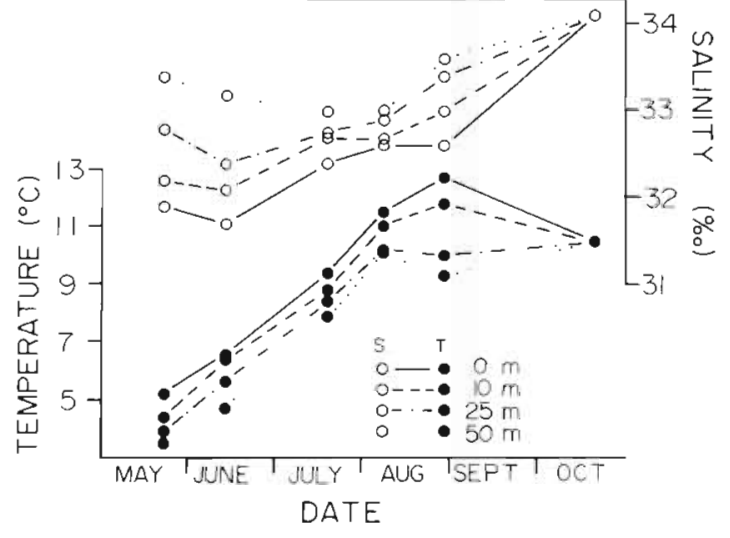

Fig. 2. Seasonal temperature and salinity profiles from 0 to $50 \mathrm{~m}$ in the lower Bay of Fundy

Green fecal pellets increased in concentration with depth, reaching a maximum of approximately 20 pellets $1^{-1}$ at the euphotic boundary (Fig. 3a). Concentration of green pellets immediately above the bottom was negligible. Brown fecal pellets showed a bimodal distribution; concentration initially decreased with

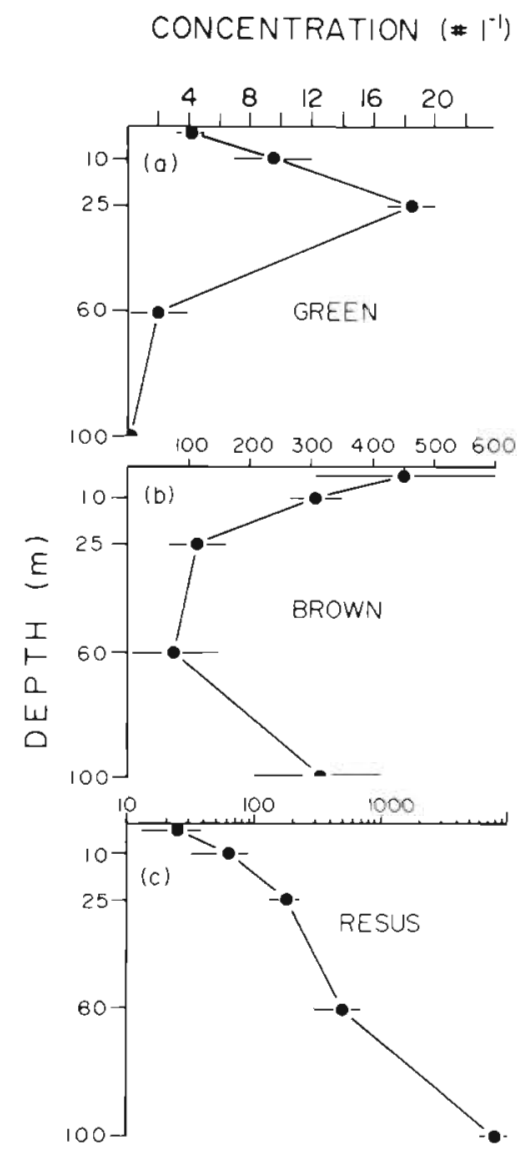

Fig. 3. Seasonally averaged concentrations of (a) green (b) brown, and (c) resuspended fecal pellets in the water column in the study area. Horizontal bars: standard errors depth, but increased immediately above the bottom (Fig. 3b). Surface and bottom concentrations of pellets reached maxima of $4501^{-1}$ and $3001^{-1}$ respectively. Resuspended fecal pellet concentration showed a logarithmic increase with depth (Fig. 3c). Maximum bottom concentrations were 3 orders of magnitude higher than those of surface waters.

Within each of the brown, green and resuspended fecal pellet categories there was no significant variation in average size with depth or season. The greatest proportion of brown pellets in the water column occurred in the 2 to $4 \times 10^{4} \mu \mathrm{m}^{3}$ volume range (Fig. $4 \mathrm{a}$ ). The size-frequency distribution of the green pellet standing stock was significantly different from that of the brown pellets. Green pellets were larger, with a peak between 40 to $100 \times 10^{4} \mathrm{um}^{3}$. The average volume of resuspended pellets was not significantly different from the brown pellets.

Pellets collected from sediment traps were approximately an order of magnitude larger in mean volume and length than those collected in bottle casts (Table 1). Also, the mean volume of fecal pellets was, on all occasions, considerably larger in traps deployed for $24 \mathrm{~h}$ than in those deployed for $5 \mathrm{~h}$.

The size-frequency distributions of intact and resuspended pellets collected from sediment traps were similar; the majority of pellets were greater than $10 \times$ $10^{4} \mu^{3}$ in volume. Significant differences were observed, however, in the proportion of intact pellets

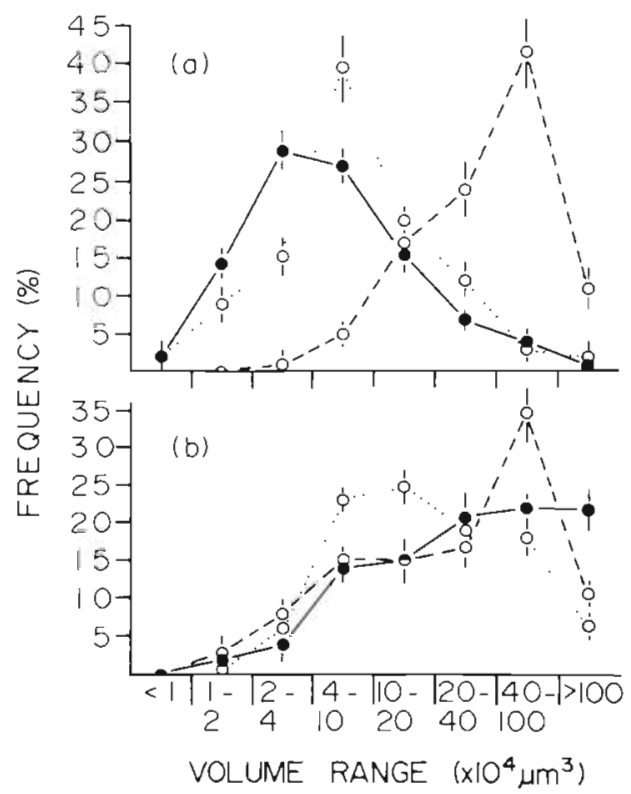

Fig. 4. Frequency-volume distributions (seasonally averaged) of fecal pellets collected by (a) bottle casts and (b) sediment traps. (a) (0-O) green pellets; $(-\infty)$ brown pellets. (b) $(0-0)$ intact pellets from $5 \mathrm{~h}$ trap deployments; $(-\bullet)$ intact pellets from $24 \mathrm{~h}$ trap deployments. $(0$ ) resuspended pellets from (a) and (b). Vertical bars: standard errors 
Table 1. Average volumes, lengths and sinking speeds (calculated from Komar et al. 1981), of fecal pellets collected by bottle casts and sediment traps in the lower Bay of Fundy. Standard errors are indicated in parentheses

\begin{tabular}{|c|c|c|c|c|}
\hline Method of collection & Pellet type & Volume $\left(10^{4} \mu \mathrm{m}^{3}\right)$ & Length (um) & Sinking speed $\left(\mathrm{m} \mathrm{d}^{-1}\right)$ \\
\hline $\begin{array}{l}\text { Bottle } \\
\text { cast }\end{array}$ & $\begin{array}{l}\text { Brown } \\
\text { Green } \\
\text { Resus. }\end{array}$ & $\begin{array}{r}9.0(2.4) \\
22.6(6.5) \\
10.9(1.5)\end{array}$ & $\begin{array}{l}63.1(4.3) \\
64.2(8.8) \\
60.5(4.4)\end{array}$ & $\begin{array}{l}19.1(4.3) \\
35.5(11.4) \\
21.8(5.6)\end{array}$ \\
\hline $\begin{array}{l}\text { Sediment } \\
\text { trap }\end{array}$ & $\begin{array}{l}\text { Intact } \cdots \\
5 \text { h TDD } \cdots \\
24 \mathrm{~h} \text { TDD } \\
\text { Resus. }\end{array}$ & $\begin{array}{c}74.6(29.4) \\
433.7(139.4) \\
48.4(9.1)\end{array}$ & $\begin{array}{l}117.6(7.8) \\
633.4(157.7) \\
94.5(3.9)\end{array}$ & $\begin{array}{c}78.6(24.4) \\
254.3(58.1) \\
58.9(9.9)\end{array}$ \\
\hline $\begin{array}{l}\text { - Resuspended fec } \\
\text {... Brown and gree }\end{array}$ & $\begin{array}{l}\text { ellets } \\
\text { cal pellets } \\
\text { ration }\end{array}$ & & & \\
\hline
\end{tabular}

in the $>100 \times 10^{4} \mathrm{\mu m}^{3}$ range; this range accounted for $20 \%$ of pellets collected over $24 \mathrm{~h}$ trap deployments, while only $10 \%$ of pellets collected over $5 \mathrm{~h}$ were in this range. There was no significant difference in the average volume of resuspended pellets caught in $5 \mathrm{~h}$ or 24 h deployments.

Mean sinking speeds of pellets from bottle casts were calculated as $27 \mathrm{~m} \mathrm{~d}^{-1}$, while those from sediment traps had mean sinking speeds of approximately $300 \mathrm{~m} \mathrm{~d}^{-1}$. The maximum time required for the peritrophic membrane to degrade was approximately $600 \mathrm{~h}$; this would occur in early summer when water temperature was lowest. In late summer, degradation time could be as little as $230 \mathrm{~h}$.

The numbers of fecal pellets sinking per hour were not significantly different in traps deployed for 5 or $24 \mathrm{~h}$ where comparisons could be made in early June (Fig. 5); however such comparisons in late July and early August showed a greater flux of pellets collected from $24 \mathrm{~h}$ deployments. Also, the total volume of fecal pellets sinking per hour was considerably lower in

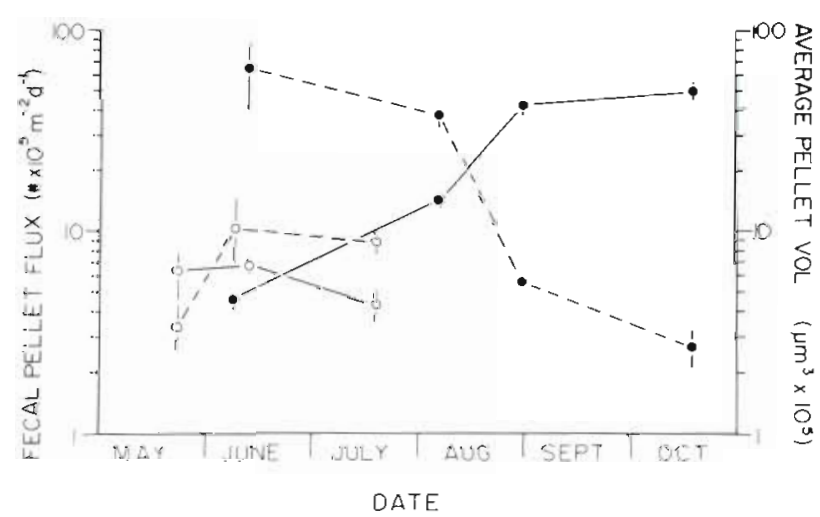

Fig. 5. Seasonal fecal pellet flux and average volume for intact pellets collected by sediment traps. (•) $24 \mathrm{~h}$ trap deployments. (o) $5 \mathrm{~h}$ trap deployments. Flux indicated by solid lines; volume represented by dashed lines. Vertical bars: standard errors traps deployed only 5 h. Flux of intact pellets collected from $24 \mathrm{~h}$ deployments increased from $\sim 4 \times 10^{5}$ pellets $\mathrm{m}^{-2} \mathrm{~d}^{-1}$ in early June to $\sim 5 \times 10^{5}$ pellets $\mathrm{m}^{-2} \mathrm{~d}^{-1}$ in late October. The average pellet volume collected was inversely related to the number of pellets sedimenting through the water column; average pellet volumes were $650 \times 10^{4} \mu^{3}$ in June and only $27.1 \times$ $10^{4} \mu \mathrm{m}^{3}$ in October (Fig. 5).

Daily sedimentation rates of fecal carbon estimated from 5 h sediment trap deployments were consistently an order of magnitude lower than daily fluxes estimated from $24 \mathrm{~h}$ trap deployments (Fig. 6). In both cases, the majority of fecal carbon was in the form of brown pellets. Resuspended pellets contributed between 1 and $30 \%$ of total fecal carbon flux.

\section{DISCUSSION}

Several factors will interact to determine both the relative contribution of fecal pellets to total carbon flux, and their significance to both pelagic and benthic processes. First, we discuss processes affecting the relatively small fecal pellets $\left(1\right.$ to $\left.40 \times 10^{4} \mu^{3}\right)$ collected by bottle casts, which form the 'standing stock'. These pellets are presumably produced by nauplii, or early copepodites (Paffenhöter \& Knowles 1979). Second, we examine the role of larger fecal pellets $(>100$ $\times 10^{4} \mu \mathrm{m}^{3}$ ) collected by sediment traps.

\section{Fate of small fecal pellets}

The probability of a fecal pellet reaching the benthos will depend upon sinking rate, coprophagy, resuspension and disintegration (Honjo \& Roman 1978). It is likely that the virtually complete loss of green fecal pellets at $100 \mathrm{~m}$ and loss of brown pellets at $60 \mathrm{~m}$ is primarily a result of coprophagy. Due to their small 


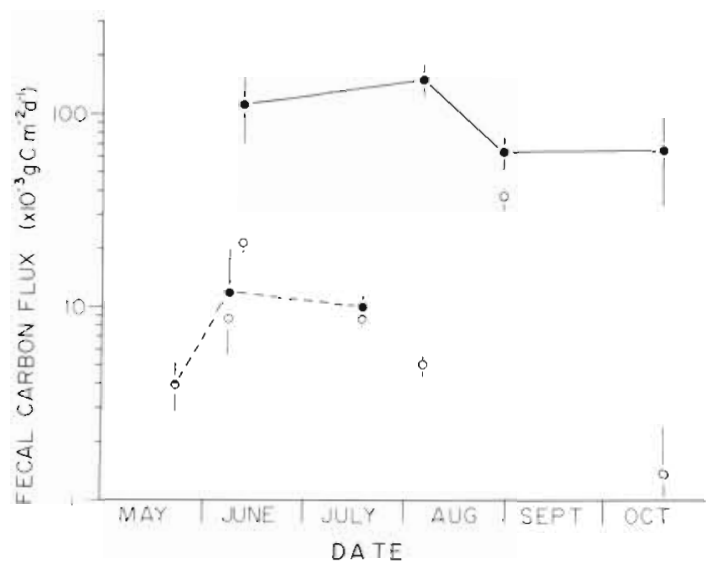

Fig. 6. Seasonal sedimentation rates of carbon in intact and resuspended pellets collected by sediment traps in the lower Bay of Fundy. (-) intact pellets collected from 24 h trap deployments; $(--)$ intact pellets collected from $5 \mathrm{~h}$ trap deployments; $(0 \cdots 0)$ resuspended pellets collected by both 5 and 24 h trap deployments. Vertical bars: standard errors

size, hydrodynamic forces would be insufficient to mechanically break these pellets. Moreover, loss of pellets from biodegradation will begin only after approximately $230 \mathrm{~h}$; therefore, loss by this mechanism should be negligible in the $100 \mathrm{~m}$ water column since these pellets have an average sinking speed of approximately $27 \mathrm{~m} \mathrm{~d}^{-1}$.

The indirect evidence of coprophagy is important to the understanding of pelagic energy flow as it implies that coupling between phytoplankton and zooplankton may not be as 'tight' as previously believed (Falkowski et al. 1983). The high concentration of fecal pellets in the upper water column provides a potentially large food source (Johannes \& Satomi 1966, Frankenberg \& Smith 1967), which can be exploited in addition to the phytoplankton. Fecal pellets, which have traditionally been classified as rapid energy exporters to the benthos and thus important regulators of benthic production, may in fact be more important to pelagic energy dynamics (Small et al. 1979).

Depth-dependent concentrations of fecal pellets may also be influenced by resuspension due to the high tidal amplitude. Using instantaneous tidal velocities for our study area from Bumpus et al. (1959), a value of 2.13 was calculated for the stratification parameter (Simpson \& Hunter 1974, Pingree 1978), indicating that the water column becomes weakly stratified, a conclusion supported by Garrett et al. (1978), and Greenberg (1979). Also, the magnitude of resuspension can be indexed by examining water column turnover time as defined by Lewis et al. (1984). Assuming total kinetic energy dissipation to be $0.3 \mathrm{~m}^{2} \mathrm{~s}^{-3}$, a minimum probable turnover time (i.e. corresponding to maximum turbulence) for the water column was calculated to be approximately $15 \mathrm{~d}$ (approximately $6 \mathrm{~m} \mathrm{~d}^{-1}$ ).

From measured concentrations of resuspended pellets throughout the water column, we can determine the theoretical upward force which suspends particles above the benthos by applying modified logistic decay equation (Broecker \& Peng 1982) to particles known to originate at the bottom. Since we have assumed that fecal pellets without peritrophic membranes must have reached the bottom, and have been subsequently resuspended, we may consider these pellets to have originated at the bottom. Assuming a relatively constant depth-dependent rate of pellet reduction due to coprophagy, we derived an upward velocity of approximately $1.3 \mathrm{~m} \mathrm{~d}^{-1}$. This is in reasonable agreement with expectations from Lewis et al. (1984), given variable tidal conditions. Although these calculations are preliminary, we believe that separate recognition of fecal pellets with and without peritrophic membranes, and a consideration of their sinking rates and removal by grazing, will lead to quantification of resuspension in coastal areas.

The effect of resuspension in our study area is therefore relatively small ( 1 to $6 \mathrm{~m} \mathrm{~d}^{-1}$ ). It is likely, therefore, that only the smallest fecal pellets (sinking speeds below $16 \mathrm{~m} \mathrm{~d}^{-1}$ ) will be influenced to the extent that their peritrophic membranes will degrade before they reach the bottom. However, since over $80 \%$ of green fecal pellets have sinking speeds $>20$ $\mathrm{m} \mathrm{d}^{-1}$, loss of these fecal pellets following membrane disintegration should be negligible in our study area. It follows that coprophagy is likely the major factor governing loss of green pellets with depth.

\section{Large pellet sedimentation}

The larger size of fecal pellets in sediment traps compared to those in bottle casts cannot be ascribed simply to size-selection biases of the collection method. Flowmeters attached to the floating sediment traps indicated current speeds of only 2 to $4 \mathrm{~cm} \mathrm{~s}^{-1}$ over the cylinders. At these speeds, laboratory experiments indicate $100 \%$ collection and retention efficiency of particles in the size range 3 to $750 \mu \mathrm{m}$ (Roff Hopcroft \& Charleton unpubl. data) for our diameter and aspect ratio of traps. Furthermore, the trap was shown to efficiently collect and retain algal cells smaller than the smallest fecal pellets (Emerson 1986). No large zooplankton likely to mechanically damage fecal pellets were observed in the cylinders upon recovery. The size-frequency distributions of trapped fecal pellets are therefore believed to be representative of particles sedimenting from the euphotic zone.

Pellets caught in the traps had comparatively rapid 
sinking rates $\left(\sim 200 \mathrm{~m} \mathrm{~d}^{-1}\right)$, enabling them to reach the bottom without being extensively grazed or degraded. Once on the bottom, fecal pellets would be broken down quickly by biodegradation (Meyer-Reil 1983), and mechanical breakage (Taghon et al. 1984). Because of these factors and the low rate of resuspension, it is unlikely that these large pellets would be resuspended in the water column, indeed, they are very rare in bottle casts. Even though small pellets collected by the traps are more susceptible to resuspension, they are not a major contributor to total pellet flux, and therefore capture of these pellets would not significantly bias flux estimates.

It is evident from our results that zooplankton behavior can influence flux estimates. The average size of intact pellets captured during diel deployments was approximately an order of magnitude larger than that measured from $5 \mathrm{~h}$ deployments, presumably a result of zooplankton vertical migration, a welldocumented phenomenon in our area (Kulka 1977). The significance of vertical migration becomes apparent when estimating fecal carbon flux over short trap deployment periods; daily fecal carbon flux calculated from $5 \mathrm{~h}$ collections is an order of magnitude lower than that measured over a diel cycle (Fig. 6).

Although studies in the past have employed longterm trap deployments, recent studies have emphasized short-term deployments (Wakeham et al. 1984). Unless careful attention is paid to the time of both deployment and retrieval, underestimates or overestimates of carbon flux may result. Because we have separated the resuspended pellets from intact pellets (with peritrophic membranes), it follows that we can measure net (primary) pellet-carbon sedimentation, an improvement on chemically measuring gross carbon sedimentation.

Acklowledgements. We are grateful to R. Hopcroft, A. Read, C. Wright and the crew of the Miss Michelle' and the Huntsman Marine Laboratory for computer and technical assistance. Special thanks are given to K. Middlebrook for valuable field support. This work was supported by an NSERC operating grant awarded to JCR.

\section{LITERATURE CITED}

Broecker, W. S., Peng, T.-H. (1982). Tracers in the sea. Columbla University. New York

Bumpus, D. F., Chevrier, J. R., Forgeron, F. D., Forrester, W D., MacGregor, D. G., Trites, R. W. (1959). Passamaquoddy fisheries investigation, Part I. Report to the International Joint Commission. Appendix I, Oceanography. International Passaquamoddy Fisheries Board

Dunbar, R. B., Berger, W. H. (1981). Fecal pellet flux to modern bottom sediment of Santa Barbara Basin (California) based on sediment trapping. Bull. geol. Soc. Am Part I. 92: 212-218
Emerson, C. W (1986). Pelagic-benthic energy coupling in the lower Bay of Fundy. M. Sc. thesis. University of Guelph

Falkowski, P. G., Vidal, J., Hopkins, T S., Rowe, G. T., Whitledge, T E., Harrison, W. G. (1983). Summer nutrient dynamics on the Middle Atlantic Bight: primary production and utilization of phytoplankton carbon. J. Plankton Res. 5 (4): 515-537

Frankenberg, D., Smith, K. L. Jr. (1967). Coprophagy in marine animals. Limnol. Oceanogr, 12: 443-450

Garnder, W. D., Hinga, K. R., Marra, J. (1983). Observations on the degradation of biogenic material in the deep ocean with implications on accuracy of sediment trap fluxes. J. mar. Res. 41 (2): 195-214

Garrett, C. J. R., Keeley, J. R., Greenberg, D. A. (1978). Tidal mixing versus thermal stratification in the Bay of Fundy and Gulf of Maine. Atmosphere-Ocean 16 (4): 403-423

Greenberg, D. A. (1979). A numerical model investigation of tidal phenomena in the Bay of Fundy and Gulf of Maine. Mar. Geodesy 2 (2): 161-187

Honjo, S. (1978). Sedimentation of materials in the Sargasso Sea at a $5367 \mathrm{~m}$ deep station. J. mar. Res. 36: 469-492

Honjo, S., Roman, M. R. (1978). Marine copepod fecal pellets: production, preservation and sedimentation. J. mar. Res. 36: 45-57

Honjo, S., Manganini, S. J., Cole, J. J. (1982). Sedimentation of biogenic matter in the deep ocean. Deep Sea Res. $29(5 \mathrm{~A})$ : $609-625$

Iseki, K., Whitney, F., Wong, C. S. (1980). Biochemical changes of sedimented matter in sediment trap in shallow coastal waters. Bull. Plankton Soc. Japan 27 (1): 27-36

Iseki, K. (1981a). Particulate organic matter transport to the deep sea by salp fecal pellets. Mar. Ecol. Prog. Ser 5: $55-60$

Iseki, K. (1981b). Vertical transport of particulate organic matter in the deep Bering Sea and Gulf of Alaska. J. oceanogr Soc. Japan 37 (3): 101-110

Johannes, R. E., Satomi, M. (1966). Composition and nutritive value of fecal pellets of a marine crustacean. Limnol. Oceanogr. 11. 191-197

Komar, P. D., Morse, A. P., Small, L. F., Fowler, S. W. (1981). An analysis of sinking rates of natural copepod and euphausid fecal pellets. Limnol. Oceanogr $26(1)$ : 172-180

Kulka, D. W. (1977). The life history of Thyssanoessa inermis (Kroyer) and the community structure of esphausids in the Bay of Fundy. M. Sc. thesis, University of Guelph

Legendre, L., Demers, S. (1984). Towards dynamic biological oceanography and limnology. Can. J. Fish. Aquat Sci. 41 (1). 2-19

Lewis, M. R., Horne, E. P. W., Cullen, J. J., Oakey, N. S., Platt, T. (1984). Turbulent motions may control phytoplankton photosynthesis in the upper ocean. Nature, Lond. 311: $49-50$

Lorenzen, C. J., Welschmeyer, N. A., Copping, A. E. (1983). Particulate organic carbon flux in the subarctic Pacific. Deep Sea Res. 30 (6A): 639-643

Lorenzen, C. J., Welschmeyer, N. A. (1983). The in situ sinking rates of herbivore fecal pellets. J. Plankton Res. 5 (6): 929-933

Meyer-Reil, L.-A. (1983). Benthic response to sedimentation events during autumn to spring at shallow water station in the Western Kiel Bight. Mar. Biol. 77: 247-256

Nowell, A. R. M., Jumars, P. A., Eckman, J. E. (1981). Effects of biological activity on the entrainment of marme sediments. Mar Geol. 42: 133-153

Oviatt, C. A., Nixon, S. W. (1975). Sediment resuspension and 
deposition in Narragansett Bay. Estuar. coast. mar. Sci. 3 : 201-217

Pace, M. L., Glasser, J. E., Pomeroy, L. R. (1984), A simulation analysis of continental shelf food webs. Mar. Biol. 82: $47-63$

Paffenhöfer, G.-A., Knowles, S. C. (1979). Ecological implications of fecal pellet size, production and consumption by copepods. J. mar. Res. 37: 35-49

Pingree, R. D. (1980). Mixing and stabilization of phytoplankton distributions on the northwest European continental shelf. In: J. H. Steele (ed.) Spatial pattern in plankton communities. Plenum Press, New York, p. 181-220

Risk, M. J., Moffat, J. S. (1977). Sedimentological significance of fecal pellets of Macoma balthica in the Minas Basin, Bay of Fundy. J. sedim. Petrol. 47: 1425-1436

Rowe, G. T., Gardner, W. D. (1979). Sedimentation rates in the slope water of the northwest Atlantic Ocean measured directly with sediment traps. J. mar. Res. 37 (3): 581-600

Sandgren, C. D., Robinson, J. V. (1984). A stratified sampling approach to compensating for non-random sedimentation of phytoplankton cells in inverted microscope settling chambers. Br. phycol. J. 19: 67-72

Simpson, J. H., Hunter, J. R. (1974). Fronts in the Irish Sea. Nature, Lond. 1250: 404-406

Small, L. F., Fowler, S. W., Unlu, M. Y (1979). Sinking rates of natural copepod fecal pellets. Mar. Biol. 51: 233-241

Smayda, T. J. (1969). Some measurements of the sinking rates of fecal pellets. Limnol. Oceanogr 14: 621-625

Sokal, R. R., Rohlf, F. J. (1981). Biometry, 2nd edn. W H. Freeman and Co., New York

Soutar, A., Kling, S. A., Crill, P. A., Duffrin, E., Bruland, K. W. (1977). Monitoring the marine environment through sedimentation. Nature, Lond. 266: 136-139
Staresinic, N., Rowe, G. T., Shaughnessey, D., Williams III, A. J. (1978). Measurement of the vertical flux of particulate organic matter with a free-drifting sediment trap. Limnol. Oceanogr 23 (3): 559-563

Suess, E. (1980). Particulate organic carbon flux in the oceans - surface productivity and oxygen utilization. Nature, Lond. 288: 260-263

Taghon, G. L., Nowell, A. R. M., Jumars, P. A. (1984). Transport and breakdown of fecal pellets: biological and sedimentological consequences. Limnol. Oceanogr. 29 (1): $64-72$

Tsunogai, S., Uematsu, M., Tanaka, N., Harada, K., Tanoue, E., Handa, N. (1980). A sediment trap experiment in Funka Bay, Japan: 'upward flux' of particulate matter in seawater. Mar. Chem. 9: 321-334

Urrere, M. A., Knauer, G. A. (1981). Zooplankton fecal pellet fluxes and vertical transport of particulate organic material in the pelagic environment. J. Plankton Res. $3(3)$ : 369-387

Wakeham, S. G., Lee, C., Farrington, J. W., Gagosian, R. B. (1984). Biogeochemistry of particulate organic matter in the oceans: results from sediment trap experiments. Deep Sea Res. 31 (5): 509-528

Wassmann, P. (1983). Sedimentation of organic and inorganic particulate material in Lindaspollene, a stratified, landlocked fjord in western Norway. Mar. Ecol. Prog. Ser, 13: $237-248$

Wiebe, P. H., Boyd, S. H., Winget, C. (1976). Particulate matter sinking to the deep-sea floor at $2000 \mathrm{~m}$ in the Tongue of the Ocean, Bahamas, with a description of a new sedimentation trap. J. mar. Res. 34 (3): 341-354 